obtained, therefore, was simply to sustain the strength of the patient; this was accomplished in the manuer described. That my diagnosis was correct is proved not only by the history of the case, but also by the voluntary admission of the patient himself. A month previous to his discharge he stated to me " that he could have eaten and drank very well all along, for that there was nothing the matter with his throat, and that he had given way at last because he saw there was no use in holding out any longer;" the truth, however, being that, by the nutriment passed into his system the equilibrium of the circulation was restored, the nervous system resumed its energies, and as a natural consequence his delusions and monomania passed away. May, 1853.

\section{CASE OF SUDDEN PROFUSE HAMORRHAGE.}

By W. H. BORHAM, EsQ., M.R.C.S.L. \& L.M. DISTRICT SURGEON-ACCOUCHEUR to ST. MARY'S hospital.

IN your "Mirror of the Practice of Medicine and Surgery," on Mr. Birkett's case of tracheotomy, page 176, you say"There are several classes of cases which tax the surgeon's skill, coolness, and decision to their fullest extent ; among these classes may be named sudden and unexpected hemorrhage, strangulated hernia, foreign bodies in the larynx, trachea, \&c.;"; and as a case included in your category has recently occurred in my practice, I am induced to refer to $m y$ note-book, and transcribe it for your columns. I was summoned to attend the case immediately, without any intimation as to its nature, and consequently went unprepared for such an accident.

Mrs. F - aged thirty-two, a greengrocer's wife, sent for me, Feb. 17th, at one P.Mr. She was stout and of lymphatic temperament; has a child eleven months old, not weaned; saw the catamenia a month since, and again three days before the accident. On my entering the room $I$ found her sitting in a chair, looking extremely blanched; her pulse was very quick and fluttering, struggling against impending syncope. She gave me incoherent and partial answers in a faltering roice, and in a few moments fainted. The attendant told me she was violently flooding, brought on by a fit of coughing. I had her immediately removed to the sofa, and placed on her back in the horizontal position. Her clothes were completely saturated with blood, which was flowing from the vagina, running down her legs and coagnlating on the floor. She lost, as far as I could judge, about three pints. I made pressure on the abdominal aorta, and directed the attendant immediately to place a napkin in cold water, wring it, and roll it in the snow (there was plenty on the ground that day), and place it over the uterus ; and I got a piece of sponge a little larger than a hen's egg, had it also rolled in the snow, and placed up the vagina. After allowing her to remain a few moments in a state of syncope, $I$ roused her and gave her a few teaspoonfuls of brandy, which revived her and "brought her to." I ordered her twenty minims of compound spirits of sulphuric ether, ten minims of diluted sulphuric acid, eight minims of Battiey's sedative solution, and an ounce of camphor mixture, to be taken every two hours; to snck ice and drink iced beverages, with light, farinaceous diet; to enjoin perfect rest and quietude, and the sponge to remain in the vagina until $I$ called again, at nine P.N., when $I$ found her comparatively comfortable, and easy, and cheerful; the hæmorrhage had quite stopped; pulse 108 , weak ; the sponge to be withdrawn and replaced with snow as at first, and remain until the morning, and to continue the acid and ether draughts.

Feb. 18th.-Ten A.M. : Free from pain, but extremely weak; got up once, but fainted directly ; no more bleeding; pulse 110; little flushed on the cheeks; tongue clean. Sponge to be remored and replaced as before; repeat the draughts without the Battley's solution, and to desist from putting the child to the breast.-Nine P.M.: Bowels not relieved since yesterday; pulse 90 , fuller ; free from pain; has a slight cough. To take, at bedtime, five grains of colocynth and blue pills; and fifteen minims of tincture of the muriate of iron, one grain of quinine, and one drachm of oxymel of squills in an ounce of camphor mixture, every four hours; sponge to be cleaned and replaced without snow.

19th.-Pulse 88; looks more cheerful; no pain; feels much stronger; appetite good. Continue the steel and quinine; to take beef-tea and boiled mutton; to be kept quiet; clean the sponge and replace it. 'The milk, which was nearly suppressed, has freely flowed into the breasts again, and she permits the child to suck, as she will not wean it. To take two glasses of port wine a day.

20th. - Much better; up and about; continue the plug; bowels regular. To take a mutton chop and porter, and continue the iron and quinine.

21st.-Convalescent. Ordered her to inject the vagina with decoction of cinchona every day, and to take a wineglass of the decoction three times a day, and to refrain from sexual intercourse for a few weeks. I could not detect any varices or other swellings in the vagina or vulva. About five years ago the patient ruptured a vessel in the lungs from lifting a heavy weight. In the blood discharged I could not detect any embryo or deciduary membrane. The blood was not menstrual. The patient micturated well throughout the illness.

I was again requested urgently to attend the case on the 4 th of March, when I found the patient suffering from accidental hæmorrhage to a considerable extent, her pains assimilating labour, with a blanched countenance and quick, fluttering pulse; and whilst conversing with her, she felt "a substance" coming from her, which was pyriform in shape, and about the size of a hen's egg, convex, rough, and shaggy exteriorly, and smooth and concave interiorly, with a longitudinal fissure dividing it half way in two. I sent her to bed, enjoined rest, light diet, and gave her a sedatire astringent mixture.

March 5th.-Very weak. To continue the mixture.

6th.-Much better; discharge less. Repeat the remedies, and take half an ounce of castor-oil.

7th.-Better. To take a bitter tonic mixture, with beef-tea, a little mutton and porter, and she has gradually recovered ever since, and is now quite well, and attending to her duties in the shop.

Dr. Druitt has kindly favoured me with his opinion of the expelled ovum, and I beg here sincerely to thank him, and hope he will allow me to quote it:-

"On examining the ovum which you were good enough to send me, I found that the cavity which contained the foetus had been ruptured, and that all traces of foetus, cord, and amnion had vanished. 'The mass consisted chiefly of blood-clot, excessively firm, and partially decolorized, mixed with other more recent coagula. By these the cavity of the chorion was compressed, and its sides brought into apposition. This blood-clot was of course infiltrated into every part of the decidual structure, and enveloped and matted together the villi of the chorion. The latter, when disentangled from it, appeared quite healthy, and so did the decidua, although just at the uterine surface its cells hcre and there displayed some few oil-globules."

I made every search for the foetus, but could not find it. The detachment of the ovum was doubtless the cause of the former hæmorrhage, which then appeared to me to be enveloped in such mystery.

Cambridge-terrace, Hyde-park, May, 1853.

\title{
A Anirror
}

OF THE PRACTICE OF

\section{MEDICINE AND SURGERY IN THE \\ HOSPITALS OF LONDON.}

Nulla est alia pro certo noscendi via, nisi quam plurimas et morborum, et dissectionum historias, tum aliorum proprias, collectas habere et inter se comparare.-Morgagn。 De Sed. et Caus. Morb., lib.i4. Frocemium.

\section{CASES OF AFFECTION OF THE KNEE-JOINT.}

1. St. Thomas's, under the care of Mr. Soutr.

2. GuY's

3. St. Bartholomew's " Ditto

4. King's College

$"$

5. ST. MARX's

6. Metropolitan Free ",

7. Charing Cross

8. ST. GEORGE's Ditto Ditto

9. LoNiDON

10. Middelesex

Surgeoxs are very frequently called upon, in nosocomial practice, to treat diseases of joints; numerons cases present themselves in the course of the year, and ample opportunities are afforded of watching the progress of these painful and too often obstinate affections. The joints most often attacked would appear to be the hip and the knee, the chronic variety being 